\title{
Experimental study of pipe-pile-based micro-scale compressed air energy storage (PPMS-CAES) for a building
}

\author{
Jingtao Zhang ${ }^{1}$, Hoyoung $\mathrm{Seo}^{2}$, Sihyun $\mathrm{Kim}^{3}$, Junyoung $\mathrm{Ko}^{4}$, and Seunghee $\mathrm{Kim}^{1, *}$ \\ ${ }^{1}$ Dept. of Civil and Environmental Engineering, University of Nebraska-Lincoln, Omaha, NE, USA \\ ${ }^{2}$ Dept. of Civil, Environmental and Construction Engineering, Texas Tech University, Lubbock, TX, USA \\ ${ }^{3}$ Dept. of Civil Engineering and Construction, Bradley University, Peoria, IL, USA \\ ${ }^{4}$ Dept. of Civil Engineering, Chungnam National University, Daejeon, Republic of Korea
}

\begin{abstract}
Compressed air energy storage (CAES) technology has been re-emerging as one of the promising options to address the challenge coming from the intermittency of renewable energy resources. Unlike the large-scale CAES, which is limited by the geologic location, small- and micro-scale CAES that uses a human-made pressure vessel is adaptable for both grid-connected and standalone distributed units equipped with the energy generation capacity. The research team recently suggested a new concept of pipepile-based micro-scale CAES (PPMS-CAES) that uses pipe-pile foundations of a building as compressed air storage vessels. To ascertain the mechanical feasibility of the new concept, we conducted lab-scale pile loading tests with a model test pile in both a loose and dense soil chamber that emulates an actual closedended pipe pile. The test pile was subjected to a repeated cycle of compressed air charge (to $P_{\max }=10 \mathrm{MPa}$ ) and discharge (to $P_{\min }=0.1 \mathrm{MPa}$ ) during the experimental study. The displacement at the top of the test pile, with and without a structural loading, in loose and dense sand, was closely monitored during the repetitive air pressurization-and-depressurization. It was observed that the vertical displacement at the pile head under different conditions was accumulated during the extended cycle of air charge and discharge, but the rate of displacement gradually attenuates during the cycle. And, the presence of structural load and density of soil affected the magnitude of the accumulated vertical displacement. From the analysis, it can be concluded that the concept of PPMS-CAES is not likely to compromise the mechanical integrity of pipe piles while showing a promising capacity for energy storage.
\end{abstract}

\section{Introduction}

Compressed air energy storage (CAES), which has the merit of being low cost, environmentally friendly, and the flexibility of scale and location, has been re-emerging as a viable option to address the intermittency of renewable energy resources (e.g., solar and wind energy). The working mechanism of conventional CAES includes the injection of compressed air into underground geological formations (e.g., salt-dome caverns, depleted natural gas reservoirs, or saline aquifers) for energy storage during an off-peak period and its release back to the surface unit to regenerate electricity for the later energy demand. CAES can be categorized as diabatic, advanced adiabatic (with or without a thermal energy storage unit), and isothermal type depending on the management of temperature. In addition to the large-scale CAES that uses underground formations to store compressed air for large energy demand, there exists an opportunity and demand for a small- or micro-scale CAES. Such small- or micro-scale CAES uses man-made vessels to store compressed air in them, which is thus not limited by the geological location

\footnotetext{
* Corresponding author: seunghee.kim@unl.edu
}

providing a promising solution for both grid-connected and standalone distributed renewable energy generation.

Pipe-pile-based micro-scale CAES (PPMS-CAES) that uses closed-ended pipe piles for both energy storage medium and load-bearing foundation is a new concept for such micro-scale CAES. Figure 1 illustrates the idea of PPMS-CAES that can store either the extra renewable energy generated from renewable energy resources during the daytime or extra electricity from the gridline to help alleviate the grid load. In detail, the ambient air is compressed by using an air motor and a compressor and then injected into the pipe piles to store the extra energy in the form of compressed air (i.e., mechanical energy). At the same time, the heat generated during air compression is stored into a separate thermal energy storage tank to lower the temperature of the inlet air in the pipe piles. Later, the compressed air is discharged to drive an air turbine and a generator to produce electricity. The separately stored heat in the thermal energy storage unit can also be combined to improve efficiency.

To date, the study of the novel idea of PPMS-CAES has been limited to the stage of analytical and numerical research [1-4]. In this study, an experimental testing setup 
was built in which a customarily fabricated stainless-steel model pile was embedded in both loose and dense soil chambers, respectively, to mimic the behavior of an actual pipe pile at a lab-scale. With that, we examined the mechanical response of the model pile, including vertical displacement at the pile head, hoop and axial strains, and temperature of the pile during pressurization and depressurization, with and without a structural load, during the repetitive cycles of air charge-and-discharge.

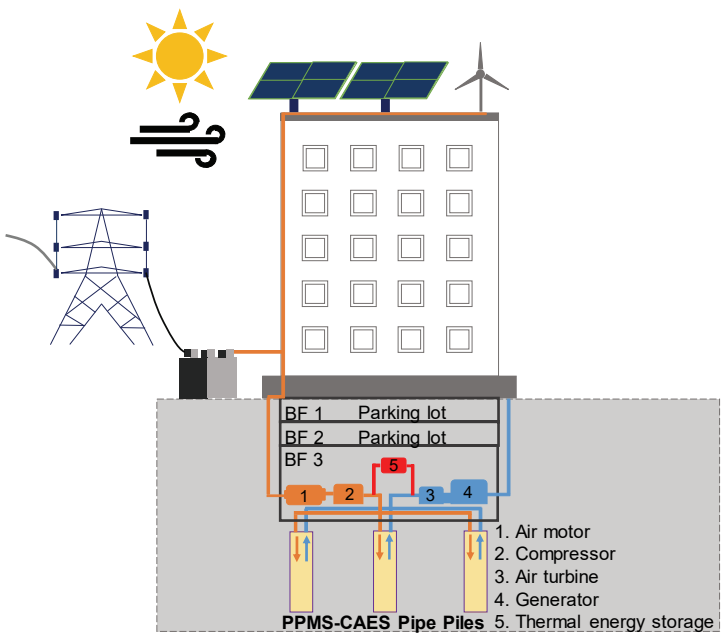

Figure 1. A schematic illustration of the concept of PPMSCAES integrated with either a renewable energy production unit or a grid.

\section{Experimental setup and procedures}

\subsection{Experimental setup}

The model test pile was prepared with a stainless-steel (grade 316) pipe. A circular plate was welded at the bottom of the pipe, forming a close-ended pipe pile with a wall thickness of $0.003 \mathrm{~m}$, an outer diameter of $0.0508 \mathrm{~m}$, and a length of $0.85 \mathrm{~m}$ (Figure 2). Relevant material properties of the model test pile are shown in Table 1. It should be mentioned that the mechanical properties of stainless steel used in this experimental study are similar to those of steel pipe piles that are commonly used in the field [5].

Table 1. Mechanical properties of stainless steel [6].

\begin{tabular}{l|l|l|l}
\hline $\begin{array}{l}\text { Yield } \\
\text { Strength } \\
(\mathrm{MPa})\end{array}$ & $\begin{array}{l}\text { Poisson's } \\
\text { Ratio }\end{array}$ & $\begin{array}{l}\text { Young's } \\
\text { Modulus } \\
(\mathrm{GPa})\end{array}$ & $\begin{array}{l}\text { Thermal } \\
\text { Expansion } \\
\left(10^{-6} / \mathrm{K}\right)\end{array}$ \\
\hline $170 \sim 310$ & $0.265 \sim 0.275$ & $190 \sim 205$ & $15 \sim 18$ \\
\hline
\end{tabular}

Multiple thermocouples (type T) and two-elements strain gauges (Tokyo Sokki) were attached near the top, middle, and bottom of the test pile to monitor the temperature and strains (hoop and axial directions), respectively, during the repetitive air charge and discharge (Figure 2). In addition, another thermocouple (type T) was attached to the air supply tube to monitor the temperature of injected air during air charge, and additional two thermocouples (type T) were attached to the outlet tube and the vent of air motor to monitor the temperature of released air during air discharge, respectively. The test pile was embedded in the soil chamber that was filled with fine-round grain silica sands (AGSCO), with a height of $1.75 \mathrm{~m}$. From the sieve analysis, $27.8 \%$ of sand was retained on US sieve \#140, $50.9 \%$ was retained on sieve $\# 200$, and $19.3 \%$ was retained on sieve \#270. The internal frictional angle of the sand is $\phi=32^{\circ}$, and the specific gravity is $\mathrm{G}_{\mathrm{s}}=2.67$. The maximum and minimum void ratio of the sand is $e_{\max }=$ 0.976 and $e_{\min }=0.655$, respectively. Two different soil conditions were prepared as soil conditions 1 and 2 in this study. For soil condition 1, the relative density of soil below the pile tip was $59 \%$, and the soil above the pile tip was $16 \%$. In soil condition 2 , the relative density of soil below the pile tip was $88 \%$, and the soil above the pile tip was $82 \%$. The soil conditions 1 and 2 belong to loosemedium dense and dense-very dense sands, respectively, according to Das [7]. For simplicity, the sand in soil conditions 1 and 2 are denoted as loose sand and dense sand conditions hereafter. Other properties of the soils are summarized in Table 2.

Table 2. Properties of sand layers in the test soil chamber.

\begin{tabular}{c|c|c|c|c}
\hline $\begin{array}{c}\text { Soil } \\
\text { condition }\end{array}$ & Soil layer & $\begin{array}{c}\gamma_{d} \\
\left(\mathrm{kN} / \mathrm{m}^{3}\right)\end{array}$ & $e$ & $D_{r}(\%)$ \\
\hline \multirow{2}{*}{1} & Below tip & 14.67 & 0.786 & 59 \\
\cline { 2 - 5 } & Above tip & 13.64 & 0.925 & 16 \\
\hline \multirow{2}{*}{2} & Below tip & 15.47 & 0.693 & 88 \\
\cline { 2 - 5 } & Above tip & 15.30 & 0.712 & 82 \\
\hline
\end{tabular}

Two stainless-steel tubes (outer diameter: $0.00635 \mathrm{~m}$ ) were connected to the test pile using a cross connector to make an inlet and outlet. An air pressure gauge (Swagelok) was mounted at the top of the cross. An LVDT (Geotac) was placed on the pile head to monitor the vertical movement of the test pile. Two air valves were connected to the tube to control the airflow. An air amplifier (Haskel AAD-30) was used to pressurize and inject the compressed air into the test pile. The air amplifier employed for this study does not involve an excessive heat generation during the air compression. Hence, the test setup emulates the advanced adiabatic or isothermal CAES, which stores the heat in separate thermal energy storage, as shown in Figure 1. An air motor (GAST 4AMNRV-92), a mini electricity generator (12V-24V 36W), an air regulator with a pressure gauge (Swagelok), and light bulbs were connected to the outlet side of the test pile to generate electricity during the air discharge. Besides, a data logger (Keysight 34972A), a computer, and a DC power supply (Keysight E3630A) were used to acquire data automatically. 


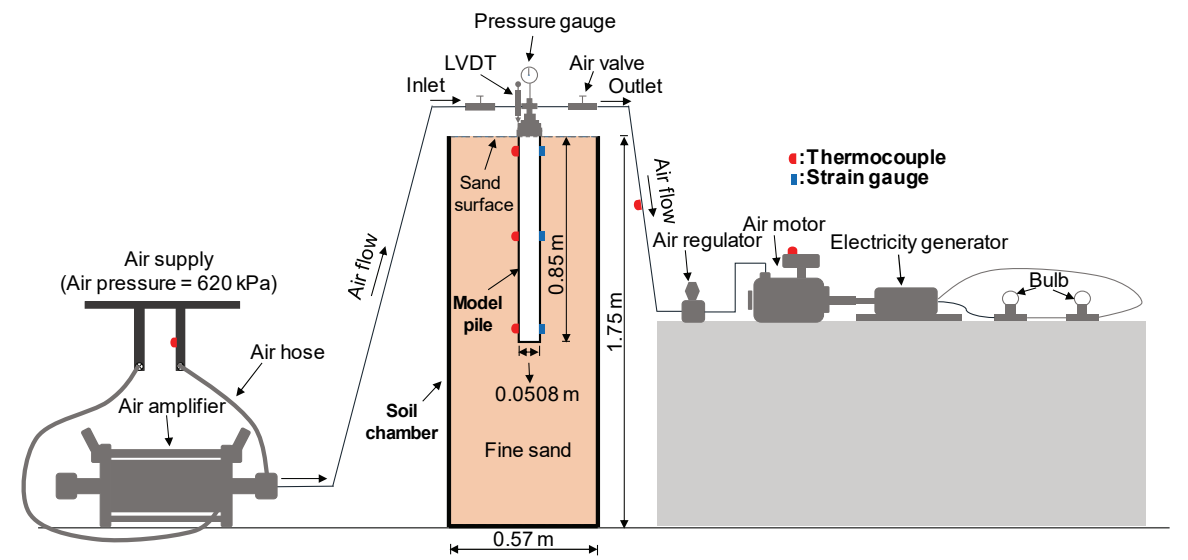

Figure 2. An experimental setup to investigate the mechanical response of a model test pile during the CAES operation

\subsection{Experimental procedures}

The experimental study of the model test pile without and with structural load was conducted in both loose and dense sand conditions to analyze the impact of the structural load and soil density on the mechanical behavior of the model pile. The room temperature was maintained at around $21-22^{\circ} \mathrm{C}$ throughout the tests.

\subsubsection{PPMS-CAES without structural load}

The air pressure inside the test pile was set to increase from $0.1 \mathrm{MPa}$ (=1 bar) to $10 \mathrm{MPa}$, which was shown not to induce any plastic deformation in the surrounding soil [1]. The datalogger, computer, and DC power supply were turned on before starting the experiment. Initially, the two air valves and the regulator were shut off. Then, the air valve on the inlet side was opened. After that, the air amplifier was set to operate to pressurize air and inject it into the test pile. When the air pressure reached $10 \mathrm{MPa}$, the air supply and inlet valves were shut off: completion of $1^{\text {st }}$ air charge (pressurization) step. After waiting for about 10 minutes, the air outlet valve was opened, and the regulator controlled the air outflow at a pressure of $35 \mathrm{kPa}$. The internal air pressure was then decreased back to 0.1 MPa: completion of $1^{\text {st }}$ air discharge (depressurization) step. After waiting for about 10 minutes again, the next cycle of air charge-and-discharge was repeated. Ten cycles of air charge-and-discharge were conducted each day for a total of five days to apply fifty cycles.

\subsubsection{PPMS-CAES with structural load}

The criteria we used to determine the static structural load was that the structural load should not exceed the ultimate bearing capacity, $Q_{u l t}=Q_{p}+Q_{s}$, of the test pile. Coyle and Castello's methods [7] were chosen to estimate the tip and frictional resistance, respectively:

$$
\begin{gathered}
Q_{p}=q^{\prime} N_{q}^{*} A_{p} \\
Q_{s}=\left(K \sigma_{o}^{\prime} \tan \delta^{\prime}\right) P L
\end{gathered}
$$

where $q^{\prime}$ : effective vertical stress at the pile tip; $N_{q}^{*}$ : bearing capacity factor; $A_{p}$ : base area of the pile; $K$ : effective earth pressure coefficient (for a pipe pile, $K=1.26) ; \sigma_{o}^{\prime}$ : vertical effective stress at the depth under consideration; $\delta^{\prime}$ : soil-pile friction angle $(0.5 \phi \sim 0.8 \phi) ; P$ : the perimeter of a pile; and $L$ : pile length. All those parameters can be calculated or found in Figure 2. With the range of $\delta^{\prime}$ and using the factor of safety of 3 , the allowable bearing capacity was estimated as $Q_{a}=Q_{u l t} / 3$ $=0.43 \mathrm{kN}-0.50 \mathrm{kN}$. Accordingly, an axial load of $0.45 \mathrm{kN}$ was chosen as the structural load for the test. The pile head settlement of $0.83 \mathrm{~mm}$ and $0.22 \mathrm{~mm}$ were recorded when the structural load was applied in the loose and dense sand conditions, respectively. After that, the same fifty cycles of air charge-and-discharge were applied to the test pile while maintaining the structural load.

A lab-scale pile test has been used as an alternative approach to evaluating the behavior of a full-scale pile. Its advantage lies in the low cost and the easily controllable soil property. Its limitation is the scaling effect. In general, there is a higher unit side resistance with the smaller diameter of a pile [8]. The ratio of a pile diameter $(D)$ to mean grain size $\left(D_{50}\right)$ is recommended to be greater than $D / D_{50}>30$ to avoid such a scale effect [9]. The diameter of the model test pile is $D=50.8 \mathrm{~mm}$, and the mean grain size is $D_{50}=0.09 \mathrm{~mm}$ in this study, which results in $D / D_{50}$ $=564>>30$. In this regard, even though the scale effect might remain to some extent, the observed behavior of the model test pile in this study can help us qualitatively assess the anticipated mechanical performance of a fullscale pipe pile during the CAES operation

\section{Experimental results}

\subsection{Temperature and strain of test pile during operation}

A summary of temperatures measured during the tests is provided in Tables 3 and 4 . It can be found that the temperature change of the test pile during the air pressurization and depressurization both in loose and 
dense sand conditions is not significant. We selected the temperature profile in the middle of the model pile (Figure 3a) as a representative for an in-depth analysis after observing that the temperature at all three points of the pile was very similar.

Table 3. Temperature measurement in loose sand

\begin{tabular}{c|c|c}
\hline & \multicolumn{2}{|c}{ Without and with structural load } \\
\hline & Pressurization & depressurization \\
\hline Model pile & $25^{\circ} \mathrm{C}$ & $20^{\circ} \mathrm{C}$ \\
\hline Air supply tube & $22^{\circ} \mathrm{C}$ & $/$ \\
\hline Air outlet tube & $/$ & $17^{\circ} \mathrm{C}$ \\
\hline Vent of air motor & $/$ & $12^{\circ} \mathrm{C}$ \\
\hline
\end{tabular}

Table 4. Temperature measurement in dense sand.

\begin{tabular}{c|c|c}
\hline & \multicolumn{2}{|c}{ Without and with structural load } \\
\hline & Pressurization & depressurization \\
\hline Model pile & $24^{\circ} \mathrm{C}$ & $20^{\circ} \mathrm{C}$ \\
\hline Air supply tube & $22^{\circ} \mathrm{C}$ & $/$ \\
\hline Air outlet tube & $/$ & $15^{\circ} \mathrm{C}$ \\
\hline Vent of air motor & $/$ & $13^{\circ} \mathrm{C}$ \\
\hline
\end{tabular}

In detail, there was about $3^{\circ} \mathrm{C}\left(=22^{\circ} \mathrm{C}-25^{\circ} \mathrm{C}\right)$ increase of the air temperature at the model test pile during air pressurization, while about $13^{\circ} \mathrm{C}\left(=25^{\circ} \mathrm{C}-12^{\circ} \mathrm{C}\right)$ of temperature decrease occurred during the air depressurization (Table 3), owing to the faster mass flow rate during the air discharge process. A similar temperature change was observed for the pile in dense sand (Table 4). The negligible temperature rise during the air compression supports that our testing environment mimics the isothermal and advanced adiabatic CAES operation with thermal energy storage.

(a)

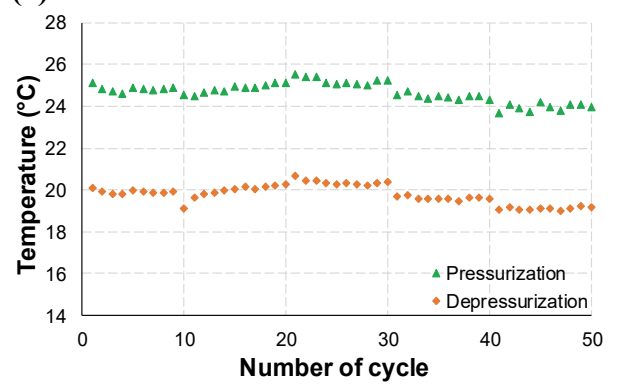

(b)

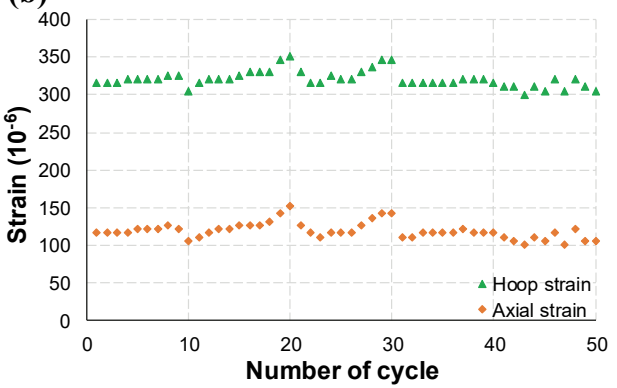

Figure 3. Experimental results of the test pile with structural load in dense sand: (a) temperature of the test pile after each pressurization and depressurization and (b) strain of the test pile after pressurization.
Similar to the temperature, the hoop and axial strains measured in the middle of the test pile were selected as representative values. It was observed that all the hoop strains were between $300 \times 10^{-6}$ and $350 \times 10^{-6}$, and all the axial strains were between $100 \times 10^{-6}$ and $150 \times 10^{-6}$. Both hoop and axial strain did not change much with the presence of structural load, which indicates the trivial impact of structural load on the mechanical response of the test pile. Figure $3 \mathrm{~b}$ shows the hoop and axial strains in the middle of the test pile with structural load in dense sand after the air pressurization. We compared the measured strain magnitudes with the yield strain of the material to check the mechanical integrity of the pile. As the ratio of the radius $(R)$ to wall thickness $(t)$ of the test pile is 8.5 , which is close to 10 , we used a thin-walled vessel theory to make a conservative calculation [4]. With that, the hoop and axial strains can be found as [8]:

$$
\begin{gathered}
\varepsilon_{H}=\frac{1}{E}\left(\sigma_{H}-v\left(\sigma_{R}+\sigma_{A}\right)\right) \\
\varepsilon_{A}=\frac{1}{E}\left(\sigma_{A}-v\left(\sigma_{H}+\sigma_{R}\right)\right)
\end{gathered}
$$

where $\sigma_{H}$ is hoop stress; $\sigma_{A}$ is axial stress $\left(\sigma_{A}=\frac{\sigma_{H}}{2}\right) ; \sigma_{R}$ is radial stress (assumed to be zero at the outer surface of test pile); $v=0.27$ is Poisson's ratio, and $E=200 \mathrm{GPa}$ is Young's modulus. The lower end of yield strength in Table 1 was chosen to make a conservative estimate; that is, hoop stress is $\sigma_{H}=170 \mathrm{MPa}$ and axial stress is $\sigma_{A}=$ $\frac{\sigma_{H}}{2}=85 \mathrm{MPa}$ at yield. Accordingly, yield hoop strain was calculated as $735 \times 10^{-6}$ and yield axial strain as $195 \times 10^{-6}$, using Equations (3) and (4). Both hoop and axial strains from our tests were smaller than these yield strain values. Hence, it implies that the repeated operation of compressed air storage would not compromise the mechanical integrity of the pile itself. However, it should be noted that the temperature fluctuation was not substantial in this study. If the temperature fluctuation is expected significant, it should also be considered for the mechanical integrity check.

\subsection{Displacement at the head of test pile}

\subsubsection{Loose sand}

Figure 4a shows the vertical displacement at the pile head without structural load after each air pressurization and depressurization during the fifty cycles of air chargedischarge processes. It was observed that the pile head moved upward by $0.1 \mathrm{~mm}$ (positive displacement) when the model pile was first pressurized to $10 \mathrm{MPa}$, and then, downward (negative displacement) when the model pile was depressurized back to $0.1 \mathrm{MPa}$. The settlement at the pile head was accumulated during the air chargedischarge cycles. After about 20 cycles, the elevation of the pile head began to be lower than its original elevation even after the pressurization. At the end of fifty cycles, the pile head moved down to $0.08 \mathrm{~mm}$ and $0.17 \mathrm{~mm}$ after the pressurization and depressurization, respectively. 
Unlike the test without structural load, the pile head began to be lower than its initial elevation even after being pressurized from the second cycle of air charge (Figure $4 b)$. The downward displacement was accumulated as the pressurization-and-depressurization cycle continued, but the rate of displacement gradually attenuated. The pile head moved downward by $1.2 \mathrm{~mm}$ and $1.3 \mathrm{~mm}$ at the end of the $50^{\text {th }}$ pressurization and depressurization, respectively, which is much greater than those without structural load. Furthermore, the gap of the pile head elevation between after pressurized and depressurized was much smaller than that without structural load. It implies that the movement of the model test pile was predominantly limited to down under the influence of structural load.

(a)

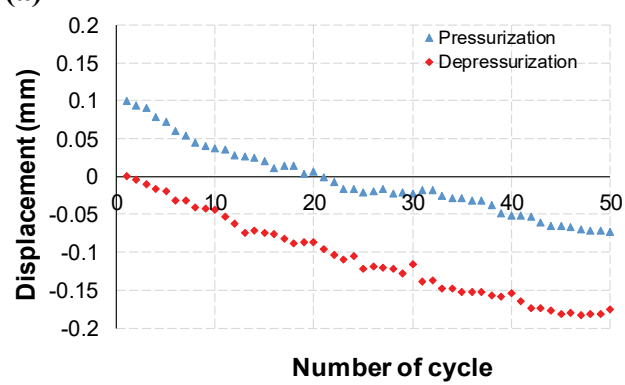

(b)

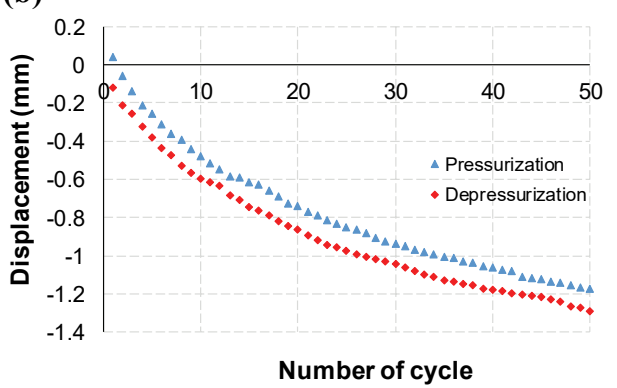

Figure 4. Displacement of the test pile in the loose sand after each air pressurization and depressurization: (a) displacement at the pile head without structural load; (b) displacement at the pile head with structural load.

\subsubsection{Dense sand}

Similar to the displacement at the pile head in the loose sand, there was an overall downward movement of the pile head without and with structural load in the dense sand (Figure 5-a and $b$ ). However, the pile head without a structural load in dense sand moved upward by $0.05 \mathrm{~mm}$ after the first pressurization, which was about one half of $0.1 \mathrm{~mm}$ from the loose sand condition. It is partly because of the larger side friction in dense sand. At around 25 cycles, the pile head began to be lower than its original elevation even after the pressurization and gradually went down to $0.08 \mathrm{~mm}$ at the end of the last pressurization. Meanwhile, the pile head moved downward to $0.02 \mathrm{~mm}$ after the first depressurization and kept going down to $0.13 \mathrm{~mm}$ at the end of the $50^{\text {th }}$ air discharge, which is smaller than $0.17 \mathrm{~mm}$ obtained in loose sand. Furthermore, the rate of the downward settlement was lower, compared to the loose sand condition, as the air charge-discharge cycle continued.

The settlement at the pile head with structural load after fifty cycles of pressurization and depressurization was around $0.7 \mathrm{~mm}$ and $0.8 \mathrm{~mm}$, respectively. Those values were again smaller than $1.2 \mathrm{~mm}$ and $1.3 \mathrm{~mm}$ from the loose sand condition, indicating the positive impact of the soil density (Figure $5 b$ ). It is also manifested by the overall smaller rate of downward settlement in dense sand during the extended cycle of air charge-discharge processes.

(a)

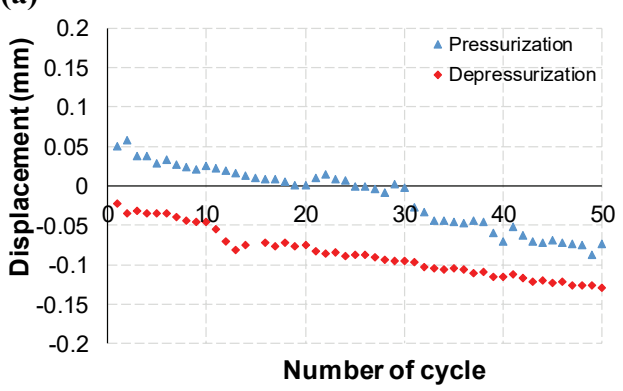

(b)

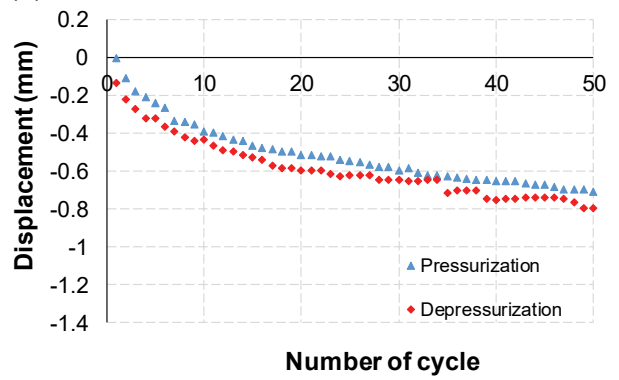

Figure 5. Displacement of the test pile in the dense sand after each air pressurization and depressurization: (a) displacement at the pile head without structural load; (b) displacement at the pile head with structural load.

It should be noted that arching near the pile tip can occur as the load transferred to the soil during the air charge and discharge. The downward movement of soils near the pile tip might reduce the confining pressure in the soil. Consequently, it could lead to a decrease of the unit skin friction near the pile tip and cause more settlement of the model test pile in the lab [11].

\section{Conclusions}

We performed laboratory experiments to examine the material integrity and mechanical response of the PPMSCAES concept using a model test pile embedded in loose and dense sand soil chamber and subjected to fifty cycles of air charge-and-discharge (air pressure range: 0.1$10 \mathrm{MPa})$. By analyzing the behavior of the test pile without and with structural load in both loose and dense sand conditions, some salient observations were made as follows:

- The air temperature increased only by $3^{\circ} \mathrm{C}$ but decreased by $13^{\circ} \mathrm{C}$, respectively, during the air pressurization and depressurization without and with 
structural load in loose sand. A similar change was observed for the pile in dense sand. The faster mass flow rate in the discharge process led to a larger temperature drop during air discharge. The overall temperature changes were not significant, which supports the emulated energy storage system in this experiment is a proxy of the isothermal or advanced adiabatic CAES operation.

- Both hoop and axial strains of the test pile were below the yield strain. Therefore, the cyclic air charge-anddischarge process is not expected to compromise the mechanical integrity of the pile. Meanwhile, there is no difference in the hoop and axial strains of the pile between with and without structural load conditions. It implies that the structural load has a minor effect on the mechanical integrity of the pile during the CAES operation.

- The head of the test pile kept moving downward for both without and with structural load in all loose and dense sand conditions. That is, the settlement of test pile after each air charge and discharge was accumulated during the extended cycles of air pressurization-and-depressurization.

- The displacement of the pile head without a structural load in loose sand continued to grow to $0.17 \mathrm{~mm}$ that is larger than that of $0.13 \mathrm{~mm}$ in dense sand at the end of the $50^{\text {th }}$ cycle of pressurization-anddepressurization. The settlement rate of the pile head with structural load in dense sand gradually attenuated more than that in loose sand, which shows a positive impact of soil density. The accumulated settlement was about $0.8 \mathrm{~mm}$ and $1.3 \mathrm{~mm}$ in dense and loose sand conditions, respectively.

This research was supported by the Nebraska Collaboration Initiative: Formed/Forming Team Seed Grant and the Start-up Grant for S. Kim at University of Nebraska-Lincoln.

\section{References}

[1] S. Kim, S. Kim, H. Seo, J. Jung, Mechanical behavior of a pile used for small-scale compressed air energy, Geo-Chicago 2016: Geotechnics for Sustainable Energy, 135-143 (2016).

[2] S. Kim, J. Ko, S. Kim, H. Seo, M. Tummalapudi, Investigation of a small-scale compressed air energy storage pile as a foundation system, Geotechnical Frontiers 2017, GSP 280, 103-112 (2017).

[3] J. Ko, S. Kim, S. Kim, H. Seo, A pipe pile for microscale compressed air energy storage: numerical investigation of pile-soil interaction, IFCEE 2018, GSP 297, 314-323 (2018).

[4] J. Ko, S. Kim, S. Kim, H. Seo, Utilizing building foundations as micro-scale compressed air energy storage vessel: Numerical study for mechanical feasibility, J. Energy Storage. 28, 101225 (2020).

[5] H.S. Al-Jubair, S.A. Abbas, Finite element analyses of laterally loaded pile groups in Um Qaser Port, Int. J. Sci. Eng. Res. 5, 662-668 (2014).
[6] https://www.azom.com/properties.aspx?Article $\mathrm{ID}=863$ (accessed June 6, 2019).

[7] B.M. Das, Principles of foundation engineering, 8th ed., Cengage Learning, Boston, (2014).

[8] J.P. Turner, F.H. Kulhawy, Physical modeling of drilled shaft side resistance in sand, Geotech. Test. J. 17, 282-290 (1994).

[9] E. Franke, G. Muth, Scale effect in 1g model tests on horizontally loaded piles, in: 11th Int. Conf. Soil Mech. Found., 1011-1014 (1985).

[10] W.B. Bickford, Advanced mechanics of materials, Addision Wesley Longman, Inc., Menlo Park, (1998).

[11]L.M. Kraft Jr, Performance of axially loaded pipe piles in sand, J. Geotech. Eng. 117, 272-296 (1991). 